\title{
Thyroid Uptake of Tc-99m and Its Agreement with I-131 for Evaluation of Hyperthyroid Function
}

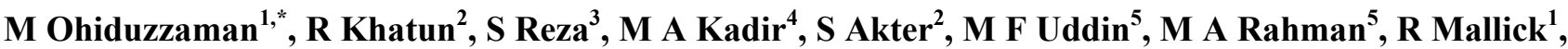 \\ M A Samad ${ }^{1}$, M M Billah ${ }^{1}$, M M Ahasan ${ }^{5}$ \\ ${ }^{1}$ Department of Physics, Jashore University of Science \& Technology, Bangladesh \\ ${ }^{2}$ Medical Physics Division, Atomic Energy Centre, Bangladesh \\ ${ }^{3}$ Institute of Nuclear Medicine \& Allied Sciences, Bangladesh \\ ${ }^{4}$ Department of Biomedical Physics and Technology, University of Dhaka, Bangladesh \\ ${ }^{5}$ Institute of Nuclear Medical Physics, BAEC, Bangladesh
}

Copyright $(2019$ by authors, all rights reserved. Authors agree that this article remains permanently open access under the terms of the Creative Commons Attribution License 4.0 International License

\begin{abstract}
Thyroid uptake and scintigraphy using Tc-99m pertechnetate has proven to be more advantageous than with I-131 iodide, since the images have better quality, the procedure is faster and the patient is submitted to a lower radiation dose. Tc-99m has been used worldwide to study the thyroid function because of a number of advantages such as short half-life, short biological half-life, short effective half-life, short retention in gland and no Beta $(\beta-)$ radiation, providing low dose to gland $(10,000$ times less than that of I-131), low cost and readily availability. Otherwise, I-131 with its high radiation burden $(1-3 \mathrm{rad} / \mathrm{mCi})$ has long half-life and causes Beta ( $\beta$-) particle emission. Its main gamma photon has high energy $(364 \mathrm{keV})$ which also causes poor image quality. The experiment is carried out at the Institute of Nuclear Medicine and Allied Sciences (INMAS), Bangladesh Atomic Energy Commission, Dhaka Medical College Hospital Campus, Dhaka-1000. In the present work, the study consists of 109 patients ( 76 female and 33 male) with ages ranging from 14 to 66 years. The patients studied with Tc-99m found to be hyperthyroid of 57 and in case of I-131, the findings were 60 . The agreement between I-131 and Tc- $99 \mathrm{~m}$ is $95 \%$ and the correlation coefficient, $r$ between Tc-99m \& $\mathrm{I}-131$ is $=0.879$, which indicates strong correlation between them. So, it is statistically significant and makes a good agreement. The outcome of this study may provide valuable information about thyroid treatment and also may play important role in the management of thyroid patient.
\end{abstract}

Keywords Thyroid, Gamma Camera, Radioisotope, Uptake, Scintigraphy, Nuclear Medicine

\section{Introduction}

The thyroid gland is the most significant organs of the endocrine system and is located in front of the trachea and below the larynx. The main function of thyroid gland is the production of thyroid hormones. The major form of thyroid hormone in the blood is thyroxine (T4), which has a longer half-life than Triiodothyronine (T3). Thyroid hormones regulate the basal metabolic rate and also influence many bodily functions, such as physical growth and development, adolescence, organ function, fertility and body temperature. Thyroid hormones secreted from the gland are $\mathrm{T} 4$ is about $80-90 \%$ and $\mathrm{T} 3$ is about $10-20 \%[1,2]$. The thyroid gland uses iodine from food to make the hormones. According to the latest estimates, about 2.5 billion people worldwide (38\% of the world's population) have insufficient iodine intake, of which 313 million are in the Southeastern Asian region that includes Bangladesh. The widespread severe iodine deficiency in all ecological zones indicates that the country as a whole is an iodine deficient region. An iodine deficiency thyroid disorder is still one of the major public health problems in Bangladesh. In 1993, a nationwide iodine deficiency disorders (IDD) survey of Bangladesh was conducted. This report showed that about $47.1 \%$ of our population had symptoms of goiter and nearly $69 \%$ population has biochemical iodine deficiency. Iodine deficiency remains the main cause of hypothyroidism worldwide [3, 4].

Appropriate diagnosis is essential for proper treatment and hence the management of the patient. Both radioiodine thyroid uptake and $99 \mathrm{mTc}$-pertechnetate uptake are the effective tools to diagnose thyroid conditions. Thyroid gland function and structure can be evaluated using uptake and scintigraphy studies. I-131 iodide, which was introduced in the late thirties, was the first radiopharmaceutical used for thyroid calculation, and for 
many years it was the main study agent used in the evaluation of thyroid function. Despite the fact that the sensitivity and specificity of in vitro tests for evaluation of thyroid function have evolved, thyroid uptake and scintigraphy still play an important role in various clinical situations $[5,6]$.

I-131 was the first radioisotope used for uptake and imaging studies of the thyroid gland. Due to long half-life and $\beta$ - particle emission I-131 produces high radiation dose to the gland. Also its main gamma photon has high energy (364 keV) which is inadequately collimated by most conventional scintillation cameras, and therefore produces poor quality images. In the United States, the use of I-131 iodide for thyroid imaging has been prohibited and its use restricted to staging and follow-up of patients with differentiated thyroidcarcinoma [7].

Nowadays, Tc-99m Pertechnetate is very much popular due to some of its useful characteristics for thyroid scintigraphy and uptake. Tc- $99 \mathrm{~m}$ in the chemical form of pertechnetate is used for thyroid scintigraphy and uptake. The similarity of volume and charge between the iodide and pertechnetate ions is the reason for the uptake of Tc-99m pertechnetate by the thyroid gland [8]. Tc-99m pertechnetate has been used worldwide to study the thyroid function because of a number of advantages, such as a short half-life (6 hours), short retention in the gland and no $\beta$ radiation, thus providing low dosage to the thyroid gland $(10,000$ times less than that of I- 131), as well as to the body as a whole. Its gamma photon of $140 \mathrm{keV}$ is ideal for imaging using scintillation cameras [9]. The purpose of this study was to perform thyroid uptake using Tc-99m and I-131, to make a comparison and hence to find out the agreement between them.

\section{Materials and Methods}

The study comprised of 109 patients, out of which 76 are female and 33 are male with ages ranging from 14 to 66 years. The experiment is carried out at the Institute of Nuclear Medicine and Allied Sciences (INMAS), Bangladesh Atomic Energy Commission, Dhaka Medical College Hospital Campus, Dhaka-1000. At first, height and weight of the patients were measured. Thyroid scintigraphy and uptake were performed after twenty (20) minutes of applying an intravenous injection of $370 \mathrm{MBq}$ of $99 \mathrm{mTc}$-pertechnetate and images were obtained using a dual head SPECT gamma camera of pixel size $1024 \times 1024$ with a zoom of 2.0. For thyroid uptake investigation, the dose of I-131 of $0.15-0.37 \mathrm{MBq}$ was administered orally and scintillation probe was used for thyroid uptake count. The number of counts present in the thyroid $(\mathrm{TH})$ was determined by an automatic region of interest (ROI) drawn around the borders of the gland. Another ROI was drawn by the same process just below the gland for background subtraction (BK) (Figure1). The full syringe counts (F) before injection and empty syringe counts (E) after injection were obtained from the images. Tc-99m uptake or total counts in the thyroid gland were obtained from the image through a region of interest (ROI) analysis in the region of the gland.

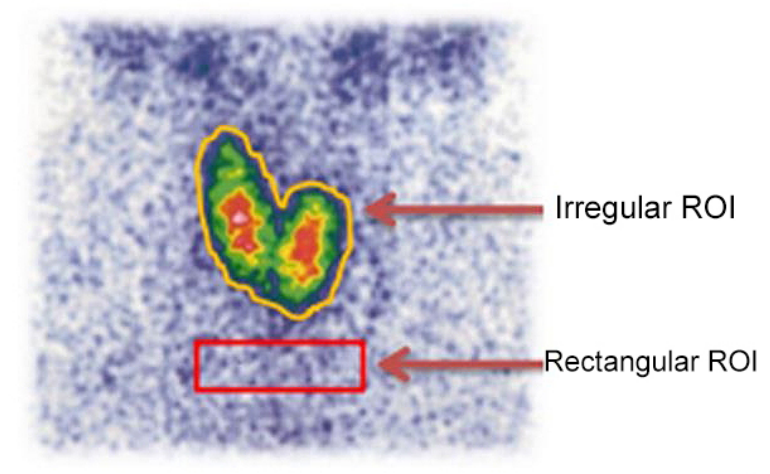

Figure 1. Irregular and rectangular background of ROI

On the contrary, blood specimens of each patient were analyzed for T3, T4 and TSH in the Radio Immuno Assay (RIA) laboratory. The normal range of these hormones used in the corresponding lab is shown in table 1.

Table 1. Normal range of T3, T4 and TSH level

\begin{tabular}{|c|c|c|}
\hline Hormone & Normal range & Unit \\
\hline T3 & $12.23-3.50$ & Nano mole per liter \\
\hline T4 & $54-174$ & Nano mole per liter \\
\hline TSH & $0.3-5.0$ & Milli internatio. unit/liter \\
\hline
\end{tabular}

Usually when the T3 and T4 level goes up and TSH level goes down from their normal range, the patient is considered as hyperthyroid and vice versa. All counts were corrected for the acquisition time and decay of technetium-99m. The thyroid uptake (TU) was calculated according to the following equation [10]:

$$
T_{C}-99 m \text { Uptake } \%=\frac{T H-B K}{F-E} \times 100 \%
$$

The thyroid uptake of I-131 for each volunteer was calculated using the following formula [11]:

$I-131$ Uptake $\%=\frac{(\text { neck count }- \text { tight count }(\text { bkg }))}{(\text { patient syringe-empty patient syringe })} \times \frac{1}{C F} \times 100 \%$

Here,

Calibration Factor $(C F)=\frac{\text { Phantom Vessel }- \text { Background }}{\text { Sandard Syringe }- \text { Empty Syringe }}$

\section{Results and Discussion}

The use of I-131 iodide for thyroid scintigraphy in nuclear medicine laboratories has been practically 
abolished for many years because of the high dosimetry and poor image quality. In the United State, the use of I-131 iodide for thyroid imaging has been banned by the FDA since the1980s and it is used for limited cases only for differentiated thyroid carcinoma and hyperthyroidism therapy [12].

Normal reference values of thyroid uptake test for radioactive iodine are obtained $10 \%-30 \%$ [13] at 24 hours and that for Tc-99m pertechnetate at 20 minutes are obtained $0.75 \%$ - 4\% in Bangladesh [10]. Patients with \% uptake values within $0.75 \%-4 \%$ or $10 \%-30 \%$ is known as euthyroid, below $<0.75 \%$ or $10 \%$ is known as hypothyroid and the above $>4 \%$ or $30 \%$ is known as hyperthyroid patients. Out of 109 patients 60 patients were found to be hyperthyroid, considering I-131 uptake as the gold-standard procedure, and using Tc-99m it is found to be 57 .

\subsection{Average Uptake Values}

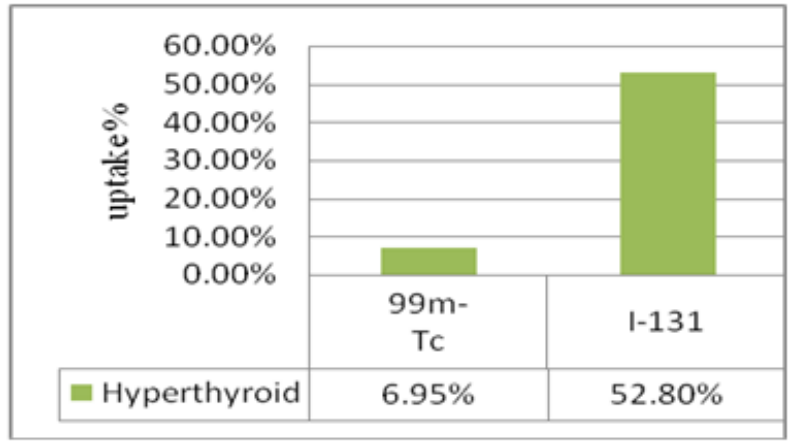

Figure 2. Average uptake values of total patients (109) using Tc-99m \& I-131

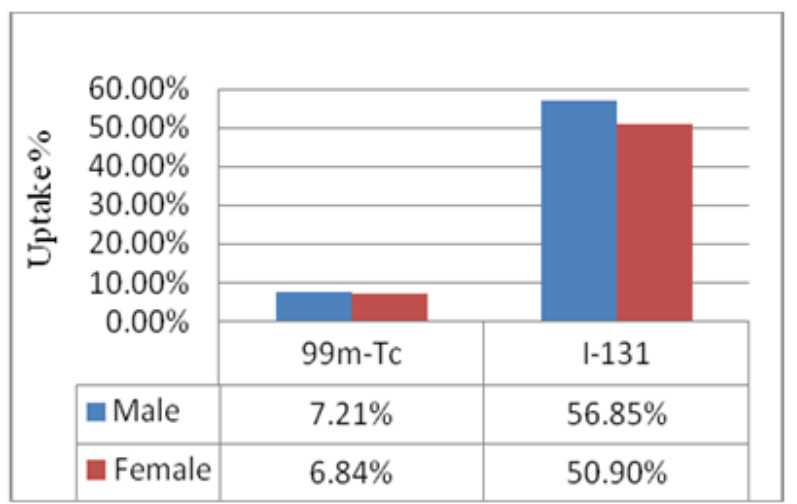

Figure 3. Average uptake values for male \& female hyperthyroid patients

The average uptake values using I-131 are found to be $52.80 \%$ and that using Tc- $99 \mathrm{~m}$ is found to be $6.95 \%$ for hyperthyroid patients, shown in Figure 2. This may be due to the high energy and longer half life of I-131 in compared with $99 \mathrm{~m}-\mathrm{Tc}$. In Figure 3 it can be shown that, for both cases (I-131 \& Tc-99m), the average uptake for male patients is greater than female patients; this may be the overactive absorption of thyroid gland. This is a random study of patients attending the Institute of Nuclear Medicine and Allied Sciences, Dhaka for thyroid function study and the sample size is not large, so no conclusion can be drawn for the considerable variation between male and female patients.

\subsection{Thyroid Uptake Test with I-131 \& 99m-Tc}

Thyroid uptake test using I-131 (Figure4a) shows 45\% of hyperthyroid patients and $55 \%$ of other patients. On the contrary, thyroid uptake test using 99m-Tc (Figure4b) shows $52 \%$ of hyperthyroid patients and $48 \%$ of other patients respectively. From these, we see that for the thyroid uptake test with $99 \mathrm{~m}-\mathrm{Tc}$, more hyperthyroid patients were detected than that of I-131. It may be due to the detective capacities of the equipment was higher.

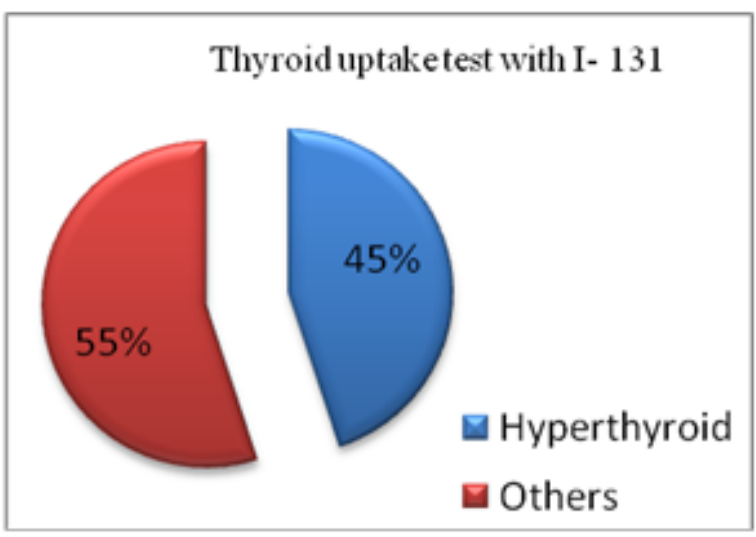

(a)

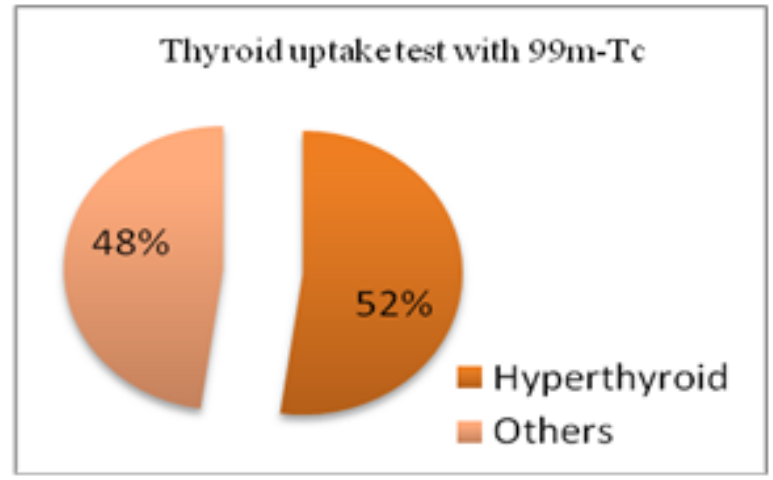

(b)

Figure 4. Pie chart for Thyroid Uptake test with(a) I-131 \& (b) $99 \mathrm{~m}-\mathrm{Tc}$

\subsection{Variation Pattern of Male and Female Patients}

Variation pattern of total male and female hyperthyroid patients were presented in Table2, to observe the responsiveness with Tc $-99 \mathrm{~m}$-and I-131.

Out of 60 patients, 54 patients are positive with both the cases of 99m-Tc and 131-I. The similar types of positive responsiveness was observed for 21 male and 39 female 
patients using the corresponding two isotopes and are found to be of 18 and 36 respectively. From this result, it can also be concluded that for these three cases, good agreement was achieved between $99 \mathrm{~m}-\mathrm{Tc}$ and 131-I.

Table 2. Data for total number of hyperthyroid patients

\begin{tabular}{|c|c|c|c|}
\hline Patients & $\begin{array}{c}\text { I-131 positive } \\
\text { \& Tc-99m } \\
\text { positive }\end{array}$ & $\begin{array}{c}\text { I-131 positive } \\
\text { \& Tc-99m } \\
\text { negative }\end{array}$ & $\begin{array}{c}\text { I-131 negative\& } \\
\text { Tc-99m positive }\end{array}$ \\
\hline $\begin{array}{c}\text { Total } \\
(60)\end{array}$ & 54 & 6 & 3 \\
\hline $\begin{array}{c}\text { Male } \\
(21)\end{array}$ & 18 & 3 & 1 \\
\hline $\begin{array}{c}\text { Female } \\
(39)\end{array}$ & 36 & 3 & 2 \\
\hline
\end{tabular}

\subsection{Variation Pattern with Respect to Age of the Patients}

The age variations for male $\&$ female of total hyperthyroid patients with $99 \mathrm{~m}-\mathrm{Tc}$ \& I-131 were mentioned in Figures 5(a) \& 5(b) respectively. For both the cases patients are the maximum at the age range of 41-50 and the minimum at the age range of 61-70. Chang Young Bang et al. [14] also reported that hyperthyroid patient is found to be higher than that of male patient at the age range of 30-39, and that is found to be lower at the age range of 60-69, which shows some similarities with the present study.

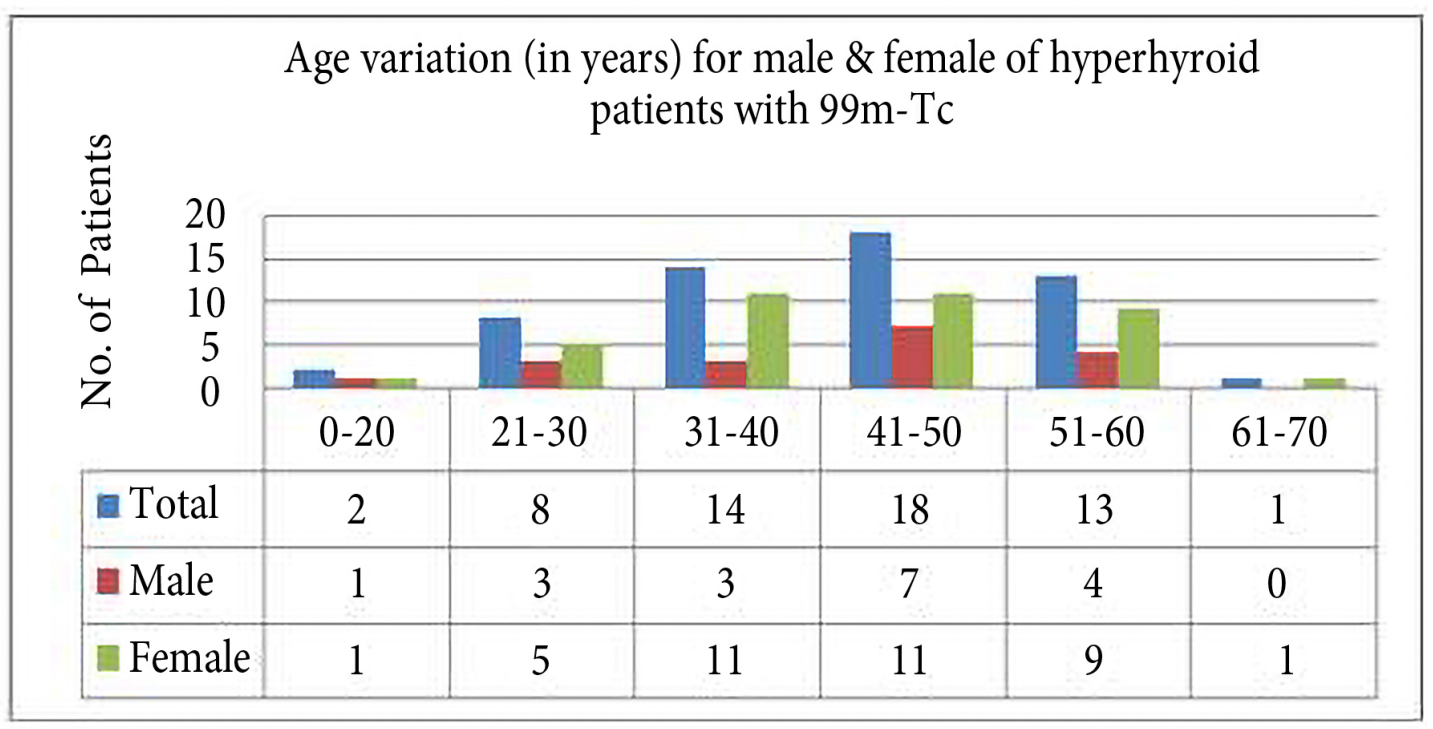

$5(a)$

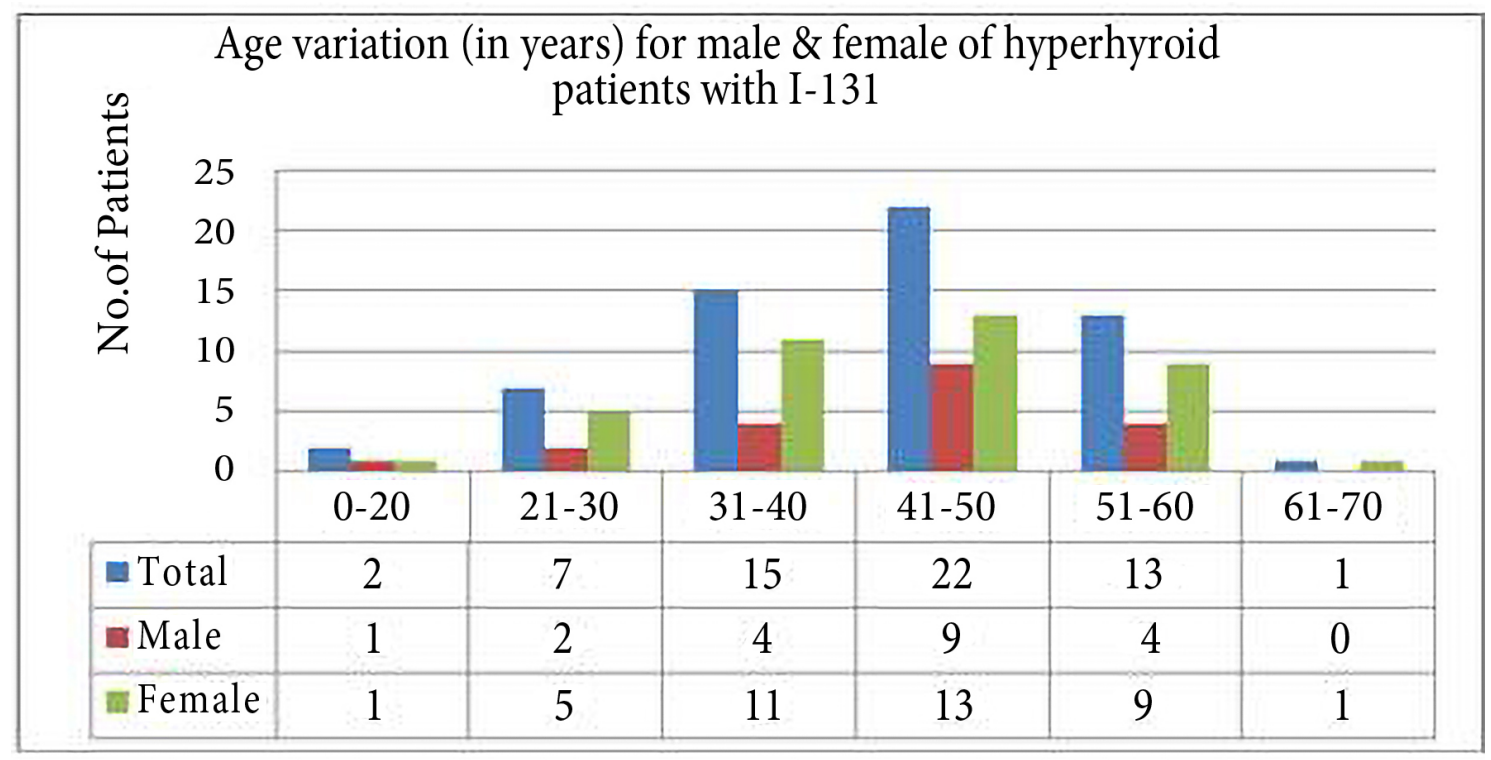

5(b)

Figure 5. Age variation for male \& female patients with(a) $99 m-T c \&$ (b) I-131 


\subsection{Level of Agreement between Tc-99m \& I-131}

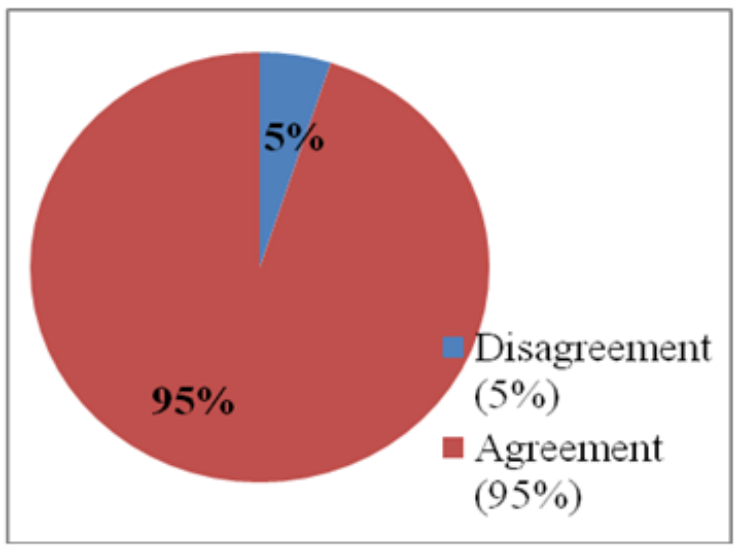

Figure 6. Agreement and disagreement of usingTc-99m \& I-131

The agreement and disagreement of using Tc-99m \& I-131 as a radiotracer for hyperthyroid patients are shown in a pie chart of Figure 6 . Here $95 \%$ patients are attained as hypothyroidism with Tc-99m \& I-131, and on the contrary $5 \%$ patients show some dissimilarity. It may be possible to reduce the disagreement if the data (thyroid and background count) can be counted through proper drawing the image of irregular region of interest (ROI) and rectangular background of ROI.

\subsection{Statistical Analysis}

All the data collected were entered and analyzed by using Statistical Package SPSS. The measure of the strength of linear dependence between two variables i.e. correlation coefficients were calculated and tested for statistical significance [15]. Figure 7 shows the scatter diagram for the comparative uptake values of the patients in both cases. The graph is drawn at maximal intersect and reveals Pearson's correlation, $r$, to be 0.879 which indicates moderate degree of relation and therefore it is statistically significant. Here $\mathrm{r}^{2}=0.773$, this means that $77 \%$ of I-131 variability could be explained by Tc-99m uptake.

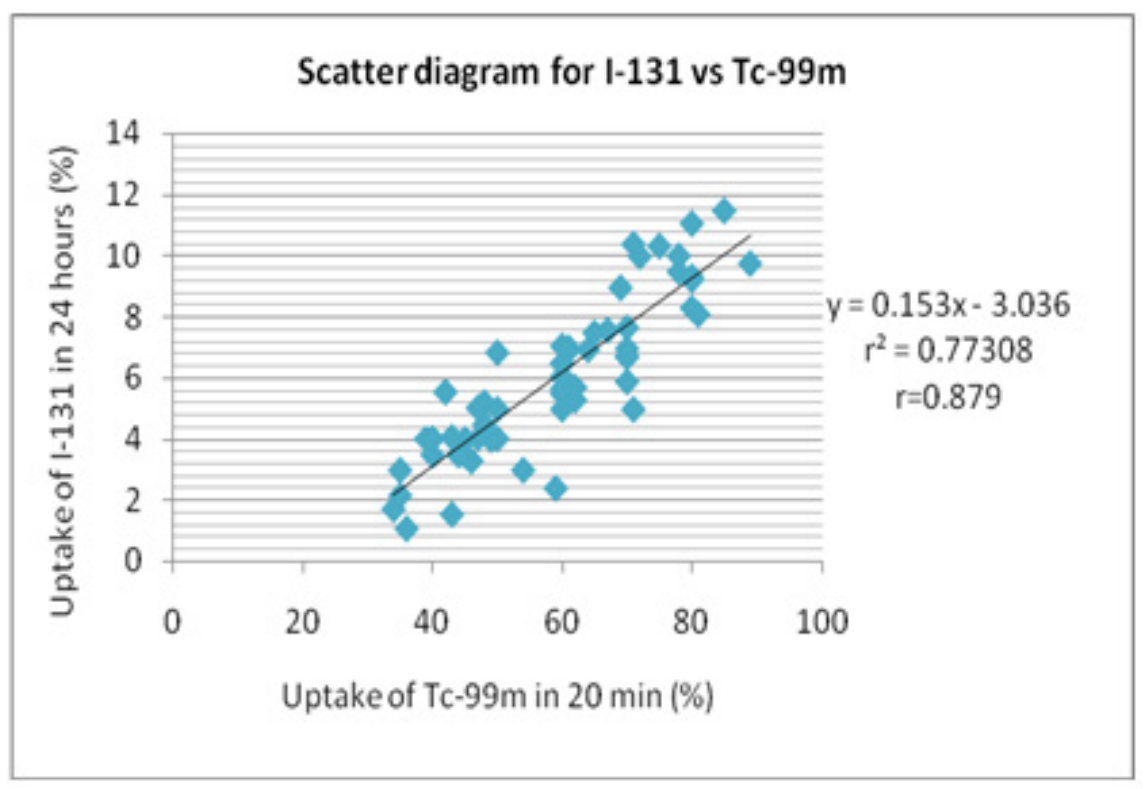

Figure 7. Scatter diagram for the uptake of Tc-99m \& I-131 


\section{Conclusions}

In this study total of 109 patients were examined who came with various types of thyroid symptoms at INMAS, Dhaka. They were investigated and found to be affected by hyperthyroidism for maximum cases. The patients studied with Tc-99m found to be hyperthyroid of 57 and in case of I-131, the findings were of 60. These hyperthyroid patients were studied with both Tc-99m \& I-131 and found to be positive for 54 patients. The correlation coefficient, $\mathrm{r}$ between Tc-99m \& I-131 is = 0.879 , which indicates strong significance and here $r^{2}=$ 0.773 . Hence this study reveals a positive and statistically significant correlation between them. This means that Tc-99m and I-131 can be used interchangeably. According to a pie chart shown in result (Figure 6), 95\% of hyperthyroid patients agree with both Tc-99m \& I-131. The results obtained in this study were also found to be in fairly good agreement with the reported data.

\section{Acknowledgements}

We are very thankful to all medical officers, scientific officers, technicians and all other stuffs of the Institute of Nuclear Medicine \& Allied Sciences (INMAS), Bangladesh Atomic Energy Commission, Dhaka Medical College Hospital Campus, Dhaka-1000 and Medical Physics Division, Atomic Energy Centre, 4 Kazi Nazrul Islam Avenue, Shahbag, Dhaka-1000, Bangladesh for their kind help during this research.

\section{REFERENCES}

[1] Irizarry, Lisandro.Thyroid Hormone Toxicity. Medscape. WedMD LLC, 2014.

[2] Ganong W.F. The Thyroid Gland in Review of Medical Physiology MeGraw Hill Companies, Newyork, 20th Edition, 307-21, 2011.

[3] Nussey S. \& Whitehead S. The Thyroid Gland in Endocrinology: An Integrated Approach. BIOS Scientific Publishers Ltd., 2001.

[4] Yusuf H.K.M., Quazi S., Khan M.R., Mahmuduzzaman M., Nahar B., Rahman M.M., Islam M.N., Khan M.A., Shahidullah M., Haque I., Baquer M. \& Panday C.S. Iodine Deficiency Disorders in Bangladesh. Indian J Pediatr, 63, 105-110, 1996.

[5] Chapman EM. History of the discovery and early use of radioactive iodine. JAMA, Vol. 15, 2042-4, 1983.

[6] Cavalieri RR, McDougall IR. "In vivo" isotopic tests and imaging. In: Braverman LE, Utiger R. Werner \& Ingbar. The thyroid. 7th ed. Philadelphia: Lippincott-Ranen, 1-372, 1996.
[7] Becker D, Charkes ND, Dworkin H, et al. Procedure guideline for thyroid scintigraphy. J Nucl Med, Vol. 37, 1264-6, 1996.

[8] Md. Mizanur Rahman, Dr. Shankar Kumar Dey, Time of maximum uptake of Technetium-99m pertechnetate $(\mathrm{TcO} 4)$ in the thyroid gland and its correlation with thyroid functional status, Bangladesh Journal of Medical Physics Vol. 8, 2015.

[9] Byeong-Cheol Ahn. Sodium Iodide Symporter for Nuclear Molecular Imaging and Gene Therapy: From Bedside to Bench and Back. Theranostics, Vol. 2, No. 4, 392-402, 2012.

[10] RH Hamunyela, T Kotze \& GM Philotheou Normal reference values for thyroid uptake of technetium-99m pertechnetate for the Namibian population, Journal of Endocrinology, Metabolism and Diabetes of South Africa, Vol. 18, No. 3, 142-147, 2013.

[11] ACR-SNM-SPR practice guideline for the performance of thyroid scintigraphy and uptake measurements, revised 2009.

[12] Thyroid uptake and scintigraphy using $99 \mathrm{mTc}$ pertechnetate: standardization in normal individuals, Sao Paulo Med J/Rev Paul Med, Vol. 120, No. 2, 45-8, 2002.

[13] Jill S. Vohs and Richard J. Petersen. Euthyroid Range Reevaluation for Radioactive Iodine Uptake Test, J. Nucl. Med. Technol. Vol. 13, No. 4, 206-208, 1985.

[14] Chan Young Bang, M. D., Choon Yul Kim, M. D., Yung 11 lee, M. D., and Yong Whee Bahk, M. D. Comparison of 99mTc- pertechnetate and 131I-iodide as Thyroid Scan Agent, Vol 13, No. 1, 1977.

[15] abc of Research Methodology \& Biostatistics, Prof. Md. Mozammel Hoque , pp 277-280. 